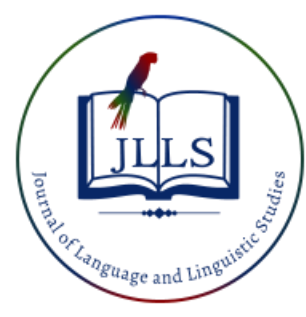

Available online at www.jlls.org

JOURNAL OF LANGUAGE AND LINGUISTIC STUDIES

ISSN: 1305-578X

Journal of Language and Linguistic Studies, 17(2), 1120-1128; 2021

\title{
An analysis of preschool children emotional intelligence using RASCH model
}

\author{
Nor Aizal Akmal Rohaizad a ${ }^{\text {ID }}$, Syamsul Bahrin Zaibon ${ }^{\text {b }}$ iD , Kasmaruddin Che Hussin ${ }^{\text {c }}$ iD \\ ${ }^{a}$ Faculty of Business, Economic and Social Development, University of Malaysia Terengganu (UMT) \\ ${ }^{b}$ School of Creative Industry Management and Performing Arts, Universiti Utara Malaysia (UUM) \\ ${ }^{c}$ Faculty of Entrepreneurship and Business, Universiti Malaysia Kelantan (UMK)
}

APA Citation:

Rohaizad, N.A.A., Zaibon, S.B., Hussin, K.C. (2021). An analysis of preschool children emotional intelligence using RASCH model. Journal of Language and Linguistic Studies, 17(2), 1120-1128. Doi: 10.52462/jlls.79

Submission Date:12/02/2021

Acceptance Date:01/05/2021

\begin{abstract}
It is very important for each individual to have a good emotional control in human well-being. In children level, they can manage their lives in a more orderly and harmonious if they have a good level of emotional intelligence (EI). However, in previous studies, there is no specific rubric developed to assess children EI. Therefore, the purpose of this research is to develop an EI rubric for children in the age group of four to six years. This study involved 20 children at preschool in Kuala Terengganu and by using the Cohen Kappa Consensus Coefficient Rating Scale formula, the research data were evaluated. To see the validity and reliability of the quantitative data, the Rasch Model analysis was utilised. To produce a competent, skilled, creative and innovative generation, the implications of this study are expected to be a basic study of children focusing on EI development in education.
\end{abstract}

Keywords: Emotional intelligence (EI); preschool; EI rubrics; RASCH; children.

\section{Introduction}

Since the emergence of a book entitled 'Emotional Intelligence' (EI), introduced by Denial Goleman in 1995, many researchers have done extensive research on it. However, although there are many instruments that have been developed to measure emotional intelligence like Mayer-SaloveyCaruso EI Test (MSCEIT) (Mayer et al., 2002), the Multi Factor Emotional Intelligence Scale (MEIS) (Salovey \& Mayer, 1990) but it is found that the existing EI instrument do not measure children's emotional intelligence (EI) (Coskun, Oksuz \& Yilmaz, 2017).

According to Gignac (2010), Tett, Fox and Wang (2005), assume that participants in the sample which had a deep objective knowledge of social, emotional skills and consistent can be measured their EI through their self-report. In children age, they are egocentric where metacognitive awareness, abstract reasoning, and objective thinking are not influenced by events. They still cannot think inductive or deductive. Their concrete thinking and the use of expressive material can aid in the learning process.

\footnotetext{
${ }^{1}$ Corresponding author:

E-mail address: aizal@umt.edu.my
} 


\section{Problem Statement}

The rapidity of today's socialization world shows that individual success is not enough to have a good level of intellectual intelligence. In fact, they also need strength in terms of good emotional intelligence (EI) growth. This has been proven by numerous studies on the development of EI that show the individuals with good EI levels will achieve a good level academic achievement, good social relationships and confidence in self-efficacy (Goroshit, 2012; Hogan, 2010; MacCann, 2011; Kotaman, 2016).

In addition, every success, excellence, and happiness of life comes from individuals with good levels of emotional stability (Brackett, 2011; Berrocal, 2016; Paavola, 2017). Emotional stability at an early age is essential for them to grow up and become individuals who can realize the aspirations of Malaysia through the 11th Malaysia Plan and the 2050 National Transformation of Being a Developed Nation in all respects, covering economic, political, social, spiritual, and psychological and culture.

However, indicators for determining the level of EI in preschool children are not yet known (Coskun et al., 2017; Peters, 2009; Rivers, 2012). Teaching and learning the application of emotional elements to preschool children under the supervision Ministry of Education Malaysia (KPM) is also problematic. the lack of teaching aids or teaching and learning modules specifically for the purpose of applying emotional elements to children has caused teachers to have difficulty in teaching and learning because there is no guidance in providing information or available syllabus and systematic knowledge based on syllabus to facilitate their teaching (Nor Aizal Akmal, Azlina \& Nora, 2012). Most of the teaching and learning emotional intelligence elements are carried out only by speaking and telling, which makes it difficult for children to grasp the information they receive and reduce their attention and interest to stay in the classroom.

In support of the Ministry of Education's goal of producing value-based citizens in accordance with the Malaysian Education Development Plan 2013-2025 (in the third shift), this study identifies that the assessment of children needs to be developed not only in the psychological aspect, but also in the aspect of education which focusing more on unity and fostering closer understanding among children. This indicator is important for being a standard benchmark for determining the children EI level. In this study, an analytical study to identify the basic elements of children EI should be carried out empirically in order to determine the criteria in the construction of child EI rubric at the preschool level.

\section{Literature Reviews}

According Mayer and Salovey (1990 \& 1997), EI is defined as the ability to control, understand and use emotions as a guide for how we think and act (Salovey \& Mayer, 1990). Emotions have a profound effect on every decision and action taken.

There is a relationship between the level of emotional intelligence and the well-being of an individual's life (Jain, 2015; Gallagher \& Vella-Brodrick, 2008). Individuals with good levels of emotional intelligence can easily adapt to new life and they also have good mental health (Bar-On, 2012; Mavroveli, Petrides, Rieffe \& Bakker, 2007).

Further, according to Dhani and Sharma (2017) and Van Rooy and Viswesvaran (2009), the findings of their study show that individuals with mental abilities and positive personality traits will have good levels of EI. Individuals with high levels of EI are able to achieve good levels of academic achievement (Maraichelvi \& Rajan, 2013; Schute, 1998). Based on study conducted by Shaheen and Shaheen (2016) and Tsaousis and Nikolaou (2002), an individual will have a healthy physical and psychological level if he has a good level of EI. 
Therefore, EI is necessary and important in the early childhood development. This is to prevent them from having any problems when they enter primary school. Such acts of quarrelling and hurting others occur due to the unstable development of children's emotions (National Preschool Standard Curriculum, 2010). Based on Fantuzzo, Bulotsky, McDermott, McWayne, Frye and Perlman (2007), Izard, Trentacosta, King and Mostow (2004), the development of EI is important to children, as this element is a rule, an encouragement to social behavior as well as positive learning behaviors.

EI is important and is fundamental to the success of a preschool environment that produces successful individuals (Fantuzzo et al, 2007; Raver \& Knitzer, 2002). According to Paavola and Evelin (2017) and Denham (2006), children who can follow instructions, pay attention and listen, able to solve problems and be patient is a one has a good EI. The National Philosophy of Education (FPK, 1996) was highlighted the importance of EI which shows efforts to create a balanced, harmonious physical, emotional, spiritual, intellectual and social people to produce knowledgeable, capable, dignified, responsible and capable of achieving personal well-being (National Preschool Standard Curriculum, 2010).

The physical, emotional, spiritual, intellectual and social development of four to six years old children also was emphasized by the National Preschool Standard Curriculum (KSPK, 2010). To equip individuals with positive skills, beliefs and concepts, the Ministry of Education Malaysia (KPM) has considered the importance of emotional which can develop a succeed in the children current environment and be prepared to address challenges and responsibilities in primary school.

\section{Methodology}

The purpose of this study is analysing the basic elements of children emotional intelligence at ages four to six years. The analysis of EI basis element was performed to construct the preschoolers' EI rubrics. The research design that will be used in this study is quantitative design to obtain the validity and reliability of the built in EI instrument. Participant will involve a preschool child in the Kuala Terengganu area.

The study participants were selected randomly based on the purpose of sampling. Researchers selected 20 children (10 boys and 10 girls) consisting of preschoolers (4 to 6 years). The selection of 20 study participants met the needs of the quantitative research in this study which clearly showed that the study participants were able to provide information up to a saturation point to avoid variant error.

The instruments used in this study are human-based, with researchers being the main tools. Researchers were also assisted by the instrumentation of the observation checklist and the interview checklist. This instrumentation is recognized by Creswell (2013) and Othman (2014) for obtaining accurate and stable data while understanding the true phenomena of the study. This checklist was constructed based on the domain of the EI indicator by Sullivan (1999), the EI indicator by Mayer et.al (2002) and the EI indicator by Goleman (1996) which was modified to fit the research needs.

Through the concept of a two-day workshop, 10 groups of two study participants will be assigned the task to perform appropriate activities that can build their EI. The Child-Centered Game Development Approach (Moser, 2012) is used as a reference to ensure that this activity is appropriate for the classroom environment.

The quantitative data to obtain the instrument reliability which using Rasch Model analysis. Data were analysed using Winsteps 3.68 .2 and results are presented in several sections: Reliability, Separation Index, Item Polarity, Item Fit and Item Misfit, Residual Principal Component Analysis (PCA) and the last one The Result of Distillation. Rasch Dichotomous Model is used to measure Malaysian children's emotional intelligence using the adapted version of Sullivan Emotional Intelligence Scale for Children (EISC) as the scale for the items were dichomous ('yes' or 'no'). Table 2 
and Table 3 shows the statistic of EISC's adaptation in order to determine the reliability of EISC's adaptation and to what extent the adequacy of separation index item instrument of the EISC's adaptation test. The Rasch model conforms to item reliability, separation index and person separation index and also person reliability is shown from the statistic Table 1.

Table 1. Summary of 59 item measure.

\begin{tabular}{|c|c|c|c|c|c|c|c|c|}
\hline & \multirow[t]{2}{*}{ Raw Score } & \multirow[t]{2}{*}{ Count } & \multirow[t]{2}{*}{ Measure } & \multirow{2}{*}{$\begin{array}{l}\text { Model } \\
\text { Error }\end{array}$} & \multirow{2}{*}{$\begin{array}{l}\text { INFIT } \\
\text { MNSQ }\end{array}$} & \multicolumn{3}{|c|}{ OUTFIT } \\
\hline & & & & & & ZSTD & MNSQ & ZSTD \\
\hline Mean & 45.0 & 50.0 & .00 & .73 & .99 & .1 & 1.12 & .0 \\
\hline S.D. & 4.5 & .0 & 1.43 & .28 & .36 & .9 & 1.78 & 1.1 \\
\hline Max. & 49.0 & 50.0 & 2.87 & 1.11 & 1.63 & 2.6 & 9.90 & 3.7 \\
\hline Min. & 32.0 & 50.0 & -1.67 & .37 & .47 & -2.3 & .05 & -1.8 \\
\hline $\begin{array}{ll}\text { Real RMSE } & .85\end{array}$ & \multicolumn{2}{|c|}{ ADJ.SD 1.15} & \multicolumn{2}{|c|}{ Separation 1.35} & \multicolumn{4}{|c|}{ Item Reliability .65} \\
\hline Model RMSE .78 & \multicolumn{2}{|c|}{ ADJ.SD 1.19} & \multicolumn{2}{|c|}{ Separation 1.53} & \multicolumn{4}{|c|}{ Item Reliability .70 } \\
\hline \multicolumn{3}{|c|}{ S.E. of Item Mean $=.20$} & & & & & & \\
\hline
\end{tabular}

Individual separation index and items can be produces by Rasch analysis. The individual isolation index is indicating from the number of strata capabilities identified in the sample group. The item separation index can show the separation of item difficulty level. The item which is more than the value of two and the value of individual isolation is considered as good. By only one or two observation can caused the value of separation index $>2.0$. Values which is not productive for the development of measurement but not demeaning is between 1.5 and 2.0. Values between 0.5 and 1.5 and the productivity measurement $<0.5$ is less productive for measurement. Value of reliability between 0.6 and 0.8 and the value which is less than 0.6 is not acceptable for reliability while the reliability value of $>0.8$ were accepted as high value.

The EISC's adaptation construct as 1.75 which individual separation index for all construct indicate that the number of strata which measure the ability of individuals are on 2 standard errors has shown in the Table 3. The EISC's adaptation constructs as 1.35 which mean person measure separation index indicates the number of strata that measured the ability of individuals on 1 standard error has shown in the Table 1 . The reliability value less than 0.8 which is less acceptable while the value more than 0.8 is acceptable and has strong value. Table 2 shown the reliability person measure for the EISC's adaptation constructs are 0.75 . These constructs have the reliability person measures $<0.8$ which is less acceptable while the reliability item measure for the EISC's adaptation constructs which shown in the Table 2 are 0.65 which is also their liability item measures $<0.8$ and less acceptable.

Table 2. Summary of 20-person measure.

\begin{tabular}{lllllllll}
\hline & $\begin{array}{l}\text { Raw } \\
\text { Score }\end{array}$ & Count & Measure & $\begin{array}{l}\text { Model } \\
\text { Error }\end{array}$ & INFIT & OUTFIT \\
& & & & & & & & \\
& & & & & & & & \\
MNSQZSTD & MNSQZSTD \\
Mean & 52.7 & 59.0 & 3.13 & .63 & .99 & .1 & 1.16 & .1 \\
S.D. & 6.8 & .0 & 1.40 & .24 & .15 & .5 & 1.79 & .9 \\
Max. & 58.0 & 59.0 & 4.82 & 1.03 & 1.50 & 2.1 & 9.90 & 3.3 \\
\hline
\end{tabular}




\begin{tabular}{|c|c|c|c|}
\hline Min. $\quad 23.0$ & -1.27 & -1.1 & .16 \\
\hline $\begin{array}{lc}\text { Real RMSE } & .69 \\
\text { Item Reliability } .75\end{array}$ & ADJ.SD 1.21 & & Separation 1.75 \\
\hline $\begin{array}{l}\text { Model RMSE } .68 \\
\text { Item Reliability } .76\end{array}$ & ADJ.SD 1.22 & & Separation 1.80 \\
\hline S.E. of Item Mean $=.22$ & & & \\
\hline
\end{tabular}

The polarity item can find a correlation coefficient of measurement-point which is known as pointmeasure correlation Coefficient (PTMEA Corr). It also can show the validity of a questionnaire which can referring to the analysis of the output program. The value of PTMEA Corr in the EISC's adaptation test instruments can be generate by Rasch measurement model.

An item is able to distinguish between the ability of respondents and a negative value or zero indicates that the link for the item response is in conflict with the variable or construct if the PTMEA Corr is high. Have several items which show negative value and zero of PTMEA Corr. The items are 10: AI10, 29: B1A, 31: B1C, 37: B3A, 38: B3B, 39: B3C, 40: B3D, 43:C1C, 45:C2B, 55: D6 and 56: D7. Therefore, it can be concluded that has several items cannot be contribute to the measurement of EISC's adaptation respondents. The items cannot discriminate or differentiate between different types of EISC's adaptation held by the respondents.

Table 3 shows a segment of principal contrast analysis of Rasch Principal Component Analysis (PCA) used to identify the uniformity of instrument dimension. The variance explained by measures is noticeably 33.10 percent which is not exceeding the minimum border of 40 percent that Rasch needed. However, the uni dimensionality of the survey instrument is confirmed by a more likely to be good unexplained variance in the first contrast $(10.1 \%)$ which is well controlled and quite far from the ceiling of 15 percent and this evidence further support the structural aspect of construct validity.

Table 3. Residual principal component analysis (in eigen value unit)

\begin{tabular}{lccc}
\hline $\begin{array}{l}\text { Table of Standardized Residual Variance (in Eigenvalue } \\
\text { units) }\end{array}$ & \multicolumn{2}{c}{ Empirical } & Modeled \\
\hline $\begin{array}{l}\text { Total raw } \\
\text { variance in } \\
\text { observations }\end{array}$ & $\begin{array}{c}61.3 \\
100.0\end{array}$ & $100.0 \%$ \\
$\begin{array}{l}\text { Raw variance } \\
\text { explained by } \\
\text { measures }\end{array}$ & 20.3 & $33.1 \%$ & $37.6 \%$ \\
$\begin{array}{l}\text { Raw variance } \\
\text { explained by } \\
\text { persons }\end{array}$ & 13.6 & $22.1 \%$ & \\
\hline $\begin{array}{l}\text { Raw variance } \\
\text { explained by } \\
\text { items }\end{array}$ & 6.7 & $10.9 \% 100.0 \%$ & $62.4 \%$ \\
$\begin{array}{l}\text { Raw } \\
\text { unexplained } \\
\text { variance (total) }\end{array}$ & 41.0 & $66.9 \% 100.0 \%$ & $62.4 \%$ \\
\hline
\end{tabular}




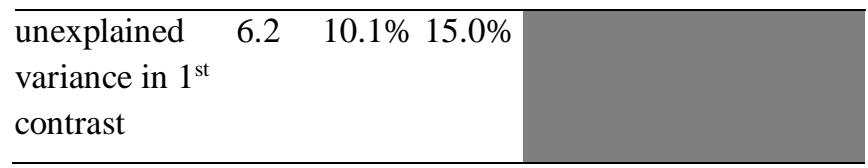

Table 4. Instrument Scale of Sullivan Emotional Intelligent for Malaysian Children after Distillation.

\begin{tabular}{|c|c|c|c|c|}
\hline & $\begin{array}{l}\text { Item } \\
\text { (After } \\
\text { Distillation) }\end{array}$ & $\begin{array}{l}\text { Item } \\
\text { (Before } \\
\text { Distillation) }\end{array}$ & $\begin{array}{l}\text { Person } \\
\text { (After } \\
\text { Distillation) }\end{array}$ & $\begin{array}{l}\text { Person } \\
\text { (Before } \\
\text { Distillation) }\end{array}$ \\
\hline Reliability & 0.92 & $(0.62)$ & 0.90 & $(0.73)$ \\
\hline $\begin{array}{l}\text { Infit } \\
\text { MNSQ } \\
\text { SD }\end{array}$ & 0.37 & $(0.34)$ & 0.41 & $(0.11)$ \\
\hline $\begin{array}{l}\text { Mean } \\
\text { Error }\end{array}$ & 0.48 & $(0.70)$ & 0.65 & $(0.60)$ \\
\hline \multicolumn{5}{|c|}{ PCA Variance Measured: $54.2 \%$ (32.1\%) } \\
\hline
\end{tabular}

Based on Table 4, the instrument has been refined to show the reliability characteristics better than before where the changes from 4.54 logic to 7.73 logic for a range of items. While for the person changes from 6.09 logic to 10.49 logic, it is shows an increase longer yardstick and encouraging for the item by 3.19 logic. The PTMEA Corr guideline show that higher increase at 54.2 percent which is over the minimum level of 40 percent needed in Rasch analysis. It is show that the clean instrument (EISC's adaptive after distillation) has enough ability to measure of what supposed to measure.

Based on the result after distillations there are several items that need dropped and leaving 37 items from the 59 items. The clean instrument (after distillations) of EISC in Malaysian children context was found to be having a higher value of reliability then the original one. This concluded that the adaptation scale after distillation can be used to measure the level of EI in Malaysian preschool children.

\section{Conclusion}

Therefore, through this study, assessments based on the elements of analytical emotional intelligence need to be identified to look at children EI which are not only from a view of psychological but in also educational aspect. EI elements and analytical rubric sections can be used as the basis for children EI measurement. In turn, this generation is believed to consist of a versatile generation with appropriate education outcomes in line with the goals of PPPM 2013-2025.

\section{Acknowledgements}

The authors would like to thanks to Knowledge Transfer Center and Industrial Network (PPIJI) Universiti Malaysia Terengganu (UMT) for granting the Knowledge and Technology Assimilation Grant Scheme KTAGS (58917) to run this research. The authors also would like to thank the support of the Ministry of Higher Education for granting Fundamental Research Grant Scheme Phase 1/2018 (59526) FRGS/1/2018/SS05/UMT/03/1. On other hand, the authors also want to thank to all participant who giving a lot of cooperation to this research. 
Conflict of interest: NIL

Source of Funding: KTAGS 2021 (58917) \& FRGS Phase 1/2018 (59526) @ FRGS/1/2018/SS05/UMT/03/

Ethical clearance: Done research committee

\section{References}

Berrocal, P.F., \& Checa, P. (2016). Editorial: Emotional Intelligence and Cognitive Abilities. Frontiers in Psychology, 7.

Brackett, M.A., Rivers, S.E., \& Salovey, P. (2011). Emotional Intelligence: Implications for Personal, Social, Academic, and Workplace Success. Social and Personality Psychology Compass, 5(1), 88103.

Coskun, K., Oksuz, Y., \& Yilmaz, H.B. (2017). Ten Years Emotional Intelligence Scale (TYEIS): Its Development, Validity and Reliability. International Journal of Assessment Tools in Education, 4(2), 122-133.

Dhani, P., \& Sharma, T. (2017). Relationship between Emotional Intelligence and Personality; A Study in Indian Context. International Business Management International Business Management, 11(5), 1133-1139.

Fantuzzo, J., Bulotsky-Shearer, R., McDermott, P., McWayne, C., Frye, D. \& Perlman, S. (2007). Investigation of Dimensions of Social-Emotional Classroom Behavior and School Readiness for Low Income Urban Preschool Children. School Psychology Review, 36, 44-62.

Gallagher, E. N. \& Vella-Brodrick, D. A. (2008). Social support and emotional intelligence as predictors of subjective well-being. Personality and Individual Differences, 44, 1551-1561.

Goleman, D. (1995). Emotional Intelligence: Why It Can Matter More Than IQ? New York: Bantam Books. http://www.abe.villanova.edu/proc2000/nO 13.pdf [ZOOl, Dis. 1I].

Goroshit, M., \& Hen, M. (2012). Emotional Intelligence: A Stable Change? International Journal of Teaching and Learning in Higher Education, 24(1), 31-42.

Hogan, M.J., James D. A. Parker, J.D.A., Wiener, J., Watters, C., Wood, L.M., \& Oke, A. (2010). Academic success in adolescence: Relationships among verbal IQ, social support and emotional intelligence. Australian Journal of Psychology, 62(1), 30-41.

Izar, Fine, S., Schultz, D., Mostow, A.J., Ackerman, B. \& Young-Storm, E. (2001). Emotion Knowledge as A Predictor of Social Behavior and Academic Competence in Children At Risk. Psychology Science, 12, 18-23.

Jain.D. R (2015). Emotional Intelligence \& its relationship with Life Satisfaction. Journal of Management, 8(1), 61-63.

Kotaman, H. (2016). Turkish prospective early childhood teachers' emotional intelligence level and its relationship to their parents' parenting styles: An international journal of teachers' professional development, 20(1), 106-122.

MacCann, C., Fogarty, G.J., Zeidner, M., Roberts, R.D. (2011). Coping mediates the relationship between emotional intelligence (EI) and academic achievement. Contemporary Educational Psychology, 36, 60-70.

Maraichelvi, A., \& Rajan, S. (2013). The Relationship between Emotional Intelligence and the Academic Performance among Final Year under Graduates. Universal Journal of Psychology, 1(2), 41-45.

Mavroveli, S., Petrides, K. V., Rieffe, C., \& Bakker, F. (2000).Trait emotional intelligence, psychological well-being and peer-rated social competence in adolescence. British Journal of Developmental Psychology, 25, 263-275. 
Mayer, J. D., \& Salovey, P. (1997). What is emotional intelligence? In P. Salovey \& D. Sluyter (Eds.), Emotional development and emotional intelligence: Educational implications (pp. 3-31). New York: Basic Books.

Mayer, J. D., DiPaolo, M. T., \& Salovey, P. (1990). Perceiving affective content in ambiguous visual stimuli: A component of emotional intelligence. Journal of Personality Assessment, 54, 772-781.

Mayer, J. D., Salovey, P., \& Caruso, D. R. (2002). Mayer-Salovey-Caruso Emotional Intelligence Test (MSCEIT) user's manual. Toronto, ON: MHS

Nikolaou, I., \& Tsaousis. I. (2002). Emotional Intelligence in the Workplace: Exploring Its Effects On Occupational Stress And Organizational Commitment. The International Journal of Organizational Analysis, 10(4), 327-342.

Paavola, L.E. (2017). The importance of emotional intelligence in early childhood. Bachelor's Thesis: Laurea University of Applied Sciences.

Peters, C., Kranzler, J.H., \& Rossen, E. (2009). Validity of the Mayer-Salovey- Caruso Emotional Intelligence Test: Youth Version- Research Edition. Canadian Journal of School Psychology, 24(1), 76-81.

Petrides, K.V. (2009). Psychometric Properties of the Trait Emotional Intelligence Questionnaire (TEIQue). Assessing Emotional Intelligence, 85-101.

Raver, C.C. \& Knitzer, J. (2002). Ready to enter: What research tells policymakers about strategies to promote social-emotional school-readiness among three-and four-year old children. New York: National Center for Children in Poverty.

Rivers, S.E., Brackett, M.A., Reyes, M.R., Mayer, J.D., Caruso, D.R., \& Salovey, P. (2012). Measuring Emotional Intelligence in Early Adolescence with the MSCEIT-YV: Psychometric Properties and Relationship with Academic Performance and Psychosocial Functioning. Journal of Psychoeducational Assessment, 30(4), 344- 366.

Schutte, N. S., Malouff, J. M., Hall, L. E., Haggerty, D. J., Cooper, J. T., Golden, C. J., \& Dornheim, L. (1998). Development and validation of a measure of emotional intelligence. Personality and Individual Differences, 25, 167-177.

Shaheen, S., \& Shaheen, H. (2016). Emotional Intelligence in Relation to Psychological Well-Being among Students. The International Journal of Indian Psychology, 3(4), 206-213.

Whitman, D.S., Rooy, D.L.V., Viswesvaran, C., \& Kraus, E. (2009). Testing the Second-Order Factor Structure and Measurement Equivalence of the Wong and Law Emotional Intelligence Scale across Gender and Ethnicity. Educational and Psychological Measurement, 69(6), 1059-1074.

\section{AUTHOR BIODATA}

Dr Nor Aizal Akmal Rohaizad is a senior lecturer in the field of educational psychology where more focus on early childhood education. Since 2012 until now, in the studies that have been carried out a lot has touched on aspects of children's emotional development. The research conducted involves a lot about the elements of emotional intelligence in the scope of child development. Apart from that, her research interest is also focused on children at the preschool level and children with disabilities or special needs. There are also several teaching and learning modules as well as books produced from the study for teachers and preschool children benefit. Apart from the research activities conducted, she also directly involved in programs related to early childhood education such as parenting programs, children's creative thinking workshops and active in participating in innovation competitions, attending seminars, and presenting papers both nationally and internationally.

Dr Syamsul Bahrin Zaibon currently is an Associate Professor of Multimedia at the School of Creative Industry Management \& Performing Arts, Universiti Utara Malaysia (UUM) and teaches various courses in the areas of creative industry and media interactive. He holds an undergraduate degree in Information Technology from Universiti Utara Malaysia (UUM), a MSc Multimedia \& Internet Computing from Loughborough 
University, and a $\mathrm{PhD}$ in Multimedia from UUM. His research is diverse and focuses on multimedia \& mobile applications, web design \& development, game-based learning, comics for learning, and edutainment. He has a number of research outputs and publications in these areas and presented papers at national and international conferences. His mail id syamsulbahrin@uum.edu.my

Dr. Kasmaruddin Che Hussin is a lecturer at Faculty of Entrepreneurship and Business, Universiti Malaysia Kelantan (UMK). He obtained his first degree and Master's degree in Business Administration (Operations Management) from MARA University of Technology (UiTM) Malaysia. He holds a doctoral degree in Management Science (majoring in Operations Management) from Lancaster University, UK. His current research focuses on three areas: (a) Business-to-Business Services, particularly on operations and supply aspects, (b) Servitization and Productivity Management in pure manufacturing firms and (c) Business Models and Operations Strategy. He has published and presented his work at various international conferences including European Operations Management Association (EurOMA). His mail id is kasmaruddin@umk.edu.my 